\title{
MODERNISME DAN POSMODERNISME DALAM DESAIN: SEBUAH PENGANTAR TEORETIS
}

\author{
Aditya Ali \\ Fakultas Komunikasi dan Desain, Universitas Informatika dan Bisnis Indonesia \\ adityaali@unibi.ac.id
}

\begin{abstract}
Abstrak
Modern adalah sebuah istilah yang banyak dihubungkan dengan kemajuan zaman diawal abad ke dua puluh. Ciri yang paling mendasar selalu dikaitkan dengan konsep revolusi industri. Penemuan mesin cetak Guttenberg selalu menjadi klaim dunia komunikasi dan desain atas era modernisme. Dalam perkembangannya, masing-masing bidang kemudian melakukan kliam-klaim baru atas modernisme melalui berbagai macam produk baik yang hanya nampak secara visual, rupa, maupun produk fungsional. Dunia seni, desain, dan arsitektur pun menjadi produsen setia modernisme. Namun nampaknya, konsep modernisme pun menemui titik jenuhnya. Konsep baru pun muncul dengan mengambil istilah yang seolah-olah menegasikan modernisme, yakni posmodernisme. Dalam perkembangnnya, istilah ini bukan hanya sekedar konsep, melainkan menjelma menjadi sebuah gerakan dan dianggap menjadi ancaman bagi modernisme, karena memiliki gaya yang mulai diminati di bidang seni, desain, dan arsitektur. Artikel ini memberikan paradigma awal mengenai modernisme dan posmodernisme khususnya dalam bidang desain dalam kerangka teoretis berdasarkan pandangan beberapa pakar terkait.
\end{abstract}

Kata kunci: modernisme, posmodernisme, seni dan desain.

\begin{abstract}
Modern is a term that has much to do with the advent of the early twentieth century. The most fundamental features are always associated with the concept of industrial revolution. The invention of Guttenberg printing press has always been the claim of the world of communication and design over the era of modernism. In its development, each field then performs new claims to modernism through a variety of products that only appear visually, visually, or functionally. The world of art, design, and architecture became a loyal manufacturer of modernism. But apparently, the concept of modernism also met the point of saturation. New concepts emerge by adopting a term that seems to negate modernism, namely postmodernism. In perkembangnnya, this term is not just a concept, but transformed into a movement and considered to be a threat to modernism, because it has a style of interest in the field of art, design, and architecture. This article provides an early paradigm of modernism and postmodernism especially in the field of design in theoretical framework based on the views of some related experts.
\end{abstract}

Keywords: modernism, postmodernism, art and design. 


\section{PENDAHULUAN}

Modernisme dan posmodernisme dalam desain adalah suatu istilah yang mengacu pada perkembangan desain di abad kedua puluh. Pembahasan tentang desain modern dan posmodern tentu tidak bisa dilepaskan dari peta sejarah dunia yang dipengaruhi situasi perang dunia pertama dan kedua, serta perkembangan desain pasca perang dunia kedua. Pengaruh perang dunia dan pasca perang dunia yang paling dominan kala itu adalah perubahan situasi sosial dan politik, terutama di negaranegara yang saat itu terlibat peperangan. Di lain pihak, kondisi sosial dan politik juga pada akhirnya berpengaruh terhadap perkembangan dunia desain, terutama pada masa-masa awal lahirnya desain modern, yang kemudian dilanjutkan dengan kelahiran desain posmodern pada awal 60-an.

Modernisme dapat diartikan sebagai suatu konsep yang berhubungan dengan hubungan manusia dengan lingkungan sekitarnya di zaman modern. Konsep modernisme ini sendiri meliputi banyak bidang ilmu termasuk seni, desain, dan kesusastraan, yang sampai saat ini -setiap bidang ilmu tersebut-- masih menjadi bahan perdebatan mengenai apa itu 'modernisme'. Pada umumnya, 'modernisme' dapat dilihat sebagai reaksi individu dan kelompok terhadap dunia atau zaman 'modern', dimana 'modern' ini dianggap sebagai dunia atau zaman yang dipengaruhi oleh praktik dan teori kapitalisme, industrialisme, dan negarabangsa, sebagi konsekwensi logis dari perang dunia. ${ }^{1}$

Sementara untuk menjelaskan apa itu posmodernisme kita bisa mengawalinya dengan memahami ungkapan Hartley bahwa "konsep posmodern digunakan secara luas dalam wacana publik, sering dengan asumsi teoritisnya yang diabaikan dan disalahpahami"'2. Thwaites, Davis, dan Mules menambahkan,

\footnotetext{
${ }^{1}$ http://id.wikipedia.org/wiki/Modernisme

2 John Hartley. Communication, Cultural, \& Media Studies. (Yogyakarta: Jalasutra, 2010). hlm. 242. Hartley menambahkan, "Untuk itu sangat berguna kiranya untuk mempertimbangkan istilah ini dalam dua cara -sebagai kondisi masyarakat (posmodernitas) dan sebagai praktik tekstual (posmodernisme)."
}

bahwa "istilah itu agak sulit untuk didefinisikan secara jelas, dan ada perbedaan pendapat yang besar tentang apakah posmodern merupakan istilah yang berguna, menyesatkan atau hanya istilah kosong dalam analisis kebudayaan"3.

Istilah posmoderisme dibangun dari kata dasar 'modernisme' ${ }^{4}$ yang kemudian diawali dengan kata 'pos'. Dalam dunia linguistik, kata 'pos' biasanya bermakna 'pasca'. Maka istilah 'posmodernisme' bisa 'disinonimkan' dengan istilah pasca-modernisme. Dalam dimensi persepsi, 'pos' bisa diartikan: keluar dari, diluar batas, meta atau lebih tinggi. Posmodernisme akhirnya dapat disimpulkan sebagai segala 'sesuatu' yang melampaui modernisme.

Dalam kaitannya dengan modernisme, gerakan posmodernisme pada akhirnya selalu dinilai sebagai ancaman terhadap modernisme. Sebagaimana yang diungkapkan Hartley (2010) bahwa para modernis 'tinggi' memandang perkembangan 'posmodernisme' menghancurkan kebenaran dan nalar atas nama relativisme dan irrealisme, menggantikan kemajuan harapan dengan desakan identitas yang dilihat sebagai retribalisasi masyarakat modern ${ }^{5}$.

\section{PEMBAHASAN}

Modernisme dalam desain berkembang pada awal abad 20 sampai lahirnya gerakan posmodernisme pasca 60-an. Desain modern telah melahirkan surealisme, kubisme, dan gerakan Dadais yang dibentuk atau sebagai akibat dari gerakan industrialisasi dan urbanisasi pada masyarakat barat. "Desain grafik modern sebagai karya grafis visual, sebenarnya sudah dimulai sejak tahun 20-an, dengan tipografi progresif dari dadaisme, futurism, de styl, konstruktivisme, dan Bauhaus,

\footnotetext{
${ }^{3}$ Tony Thwaites, Lloyd Davis, dan Warwick Mules. Introducing Cultural and Media Studies. (Yogyakarta: Jalasutra, 2009). hlm. 328.

${ }^{4}$ Secara etimologi, kata modern berasal dari bahasa latin modo, yang berarti "barusan". Modernisme adalah paham tentang modern.

${ }^{5}$ John Hartley. Communication, Cultural, \& Media Studies. (Yogyakarta: Jalasutra, 2010). hlm. 200.
} 
yang mencoba membawa pendekatan modern dalam desain grafis"6.

Desain pada masa modernisme ditandai dengan terbentuknya kelompok seniman yang tergabung dalam nama "de styl" (The Style) yang kemudian menerbitkan sebuah majalah dengan nama yang sama. Tujuannya menciptakan estetika baru dengan menggunakan, antara lain, bahasa visual yang elementer, seperti bentuk-bentuk geometris ${ }^{7}$. Pada masa modern juga berdiri sebuah sekolah seni dan desain dengan nama "Bauhaus". "Bauhaus merupakan suatu gejala yang istimewa dalam sejarah desain modern, dimana tumbuh benih-benih ide yang kemudian berpengaruh pada era pasca-1945. Pada era ini lahir karya-karya klasik yang akan menjadi dasar gaya internasional atau international style."

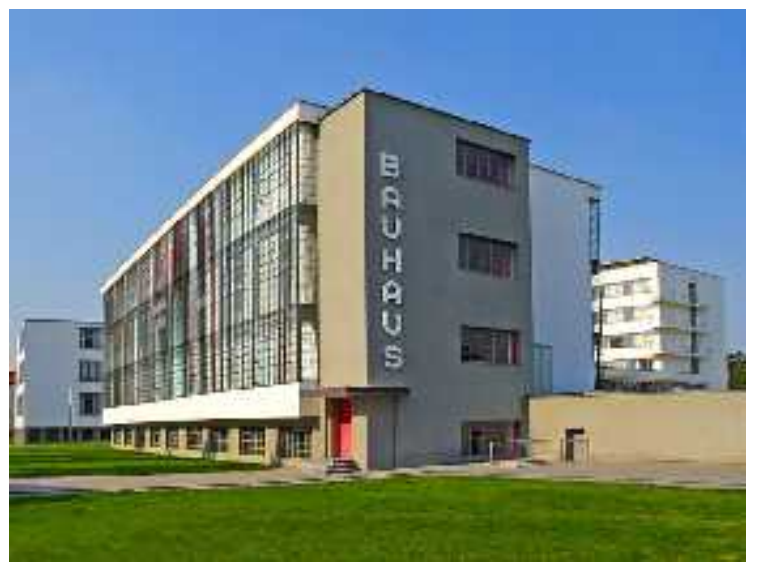

Gambar 1. Sekolah Bauhaus saat ini (Sumber:https://media1.britannica.com/ebmedia/29/182729-131-5ACDC908.jpg)

Dalam pandangan desain modern, sebuah karya desain akan dipandang memiliki nilai

\footnotetext{
6 Widagdo. Desain dan Kebudayaan. (Bandung: Penerbit ITB). hlm189.

7 Widagdo. Desain dan Kebudayaan. (Bandung: Penerbit ITB). Hlm 165, 173. "De Styl tidak terlalu tertarik dengan kenyataan seperti industrialisasi dan produksi massa dan hubungannya dengan desain. Ia lebih tertarik pada ide filosofis desain daripada realitas sehari-hari."

8 Widagdo. Desain dan Kebudayaan. (Bandung: Penerbit ITB). hlm165, 177.
}

tinggi apabila diciptakan dengan memperhatikan patokan-patokan yang logis dan wajar. Desain modern mencoba menghubungkan antara konsep, ide, realitas, dan fungsi atau kegunaan. Institusi seperti "Werkbund" di Jerman yang didirikan pada tahun 1908 berfungsi sebagai institusi yang memberikan edukasi tentang desain kepada para desainernya untuk bisa memahami kebutuhan pasar. Di samping itu pula Werkbund memberikan jasa konsultasi bagi para produsen produk dan pengusaha untuk bisa memproduksi desain yang baik yang disesuaikan dengan kebutuhan konsumen.

Herbert Lindinger

(Ulm) memformulasikan desain yang bagus atau yang dapat dimasukkan ke dalam kategori Die Gute Form adalah yang memenuhi kriteria "10 Perintah" (Inggris: The Ten Commandments, Jerman: Die Zehn Gebote): tingkat kegunaan yang tinggi, aman, produk berumur panjang dan tidak cepat using, ergonomis, mempunyai watak mandiri dari segi teknis maupun bentuk, mempunyai tingkat kesesuaian yang tinggi dalam lingkungannya (Umfeldbeziehungen), ramah lingkungan, cara kerja benda mudah dipahami (Gebruchvisualisierung), kualitas bentuk yang tinggi, mampu menstimuli perasaan. $^{9}$

Dalam perkembangan selanjutnya, desain modern nampaknya telah memasuki titik jenuh setelah international style mendapatkan kritik tajam karena dinilai tidak relevan lagi dengan perubahan budaya yang semakin cepat. Posmodernisme pun akhirnya mendapatkan gilirannya untuk berkiprah dalam sejarah perkembangan desain. Konsep ini posmodernisme-- pada awalnya adalah suatu konsep tentang cara berpikir baru --melahirkan ide-ide diluar kebiasaan-- yang berkembang pada bidang seni dan filsafat.

Dalam buku What is Pos-Modernism? Charles Jencks mengungkapkan tentang makna posmodernisme adalah adalah campuran antara macam-macam tradisi dan masa lalu. PosModernisme adalah kelanjutan dari modernisme, sekaligus melampaui modernisme.

\footnotetext{
${ }^{9}$ Widagdo. Desain dan Kebudayaan. (Bandung: Penerbit ITB). hlm185.
} 
Ciri khas karya-karyanya adalah makna ganda, ironi, banyaknya pilihan, konflik, dan terpecahnya berbagai tradisi, karena heterogenitas sangat memadai bagi pluralisme. ${ }^{10}$

Posmodernisme yang diakui berkembang sejak awal tahun 60-an telah diklaim sebagai gerakan 'pembaharuan' dari modernisme. Ia adalah gerakan kreatif yang mempertanyakan kembali tentang ide-ide dan tentang realitas. Kaum "posmo" mencoba mendekonstruksi aturan-aturan dalam dalam desain, yakni suatu reaksi terhadap gerakan modernisme yang dianggap formal. Posmodernisme sampai saat ini terus berupaya menjadi kekuatan yang dominan dalam pemikiran kreatif.

Salah satu contoh yang bagus dari apa yang ada dalam teori posmodernis ada pada ada pada cetakan multi gambar Andy Warhol dari lukisan terkenal Leonardo Da Vinci. Mona Lisa. Cetakan tersebut memperlihatkan bahwa keunikan, aura artistik, Mona Lisa dihancurkan oleh daya reproduksi tak terbatas melalui cetak kain sutra yang digunakan oleh Andy Warhol. Malahan, lukisan itu menjadi sebuah lelucon judul cetakan itu adalah "Thirty are better than One" (Tiga Puluh lebih baik dibandingkan Satu). ${ }^{11}$

Posmodernisme memberontak pada prinsip-prinsip desain seperti keseimbangan dan keteraturan. Elemen-eleman visual tidak lagi berdiri sendiri, melainkan menjadi bagian yang saling 'memuji' sekaligus 'mencerca' satu sama lain. Kaum 'posmo' mencoba mendobrak formfollows-function menjadi form-follow-fun, dan mungkin tak lama lagi akan berkembang sebagai form-follows-fantasy. Elemen elemen visual, garis, bentuk, warna, ilustrasi, fotografi, tipografi, dan tekstur bisa dengan bebas dimainkan. Respon terhadap karya ini indah,

${ }^{10}$ Gema Wahyudi. (2011, 5 Mei). Modernisme dan Posmodernisme : Pengaruhnya Terhadap Dunia Desain. Diakses 20 Desember 2013, dari http://gemawahyudi.wordpress.com/2011/05/05/mod ernisme-dan-posmodernisme-pengaruhnya-terhadapdunia-desain/. Pengertian tentang posmodernisme ini diambil dari buku Charles Jencks (1989). What is Pos-modernism? New York: St Matin's Press.

${ }^{11}$ Dominic Strinati. Popular Culture. (Yogyakarta: Jejak, 2007) hlm. 258. bagus, dan baik bukan lagi hal yang ditargetkan dalam desain posmodern, orang justru bebas mengatakan respon dan kritik apapun tentang sebuah karya desain.

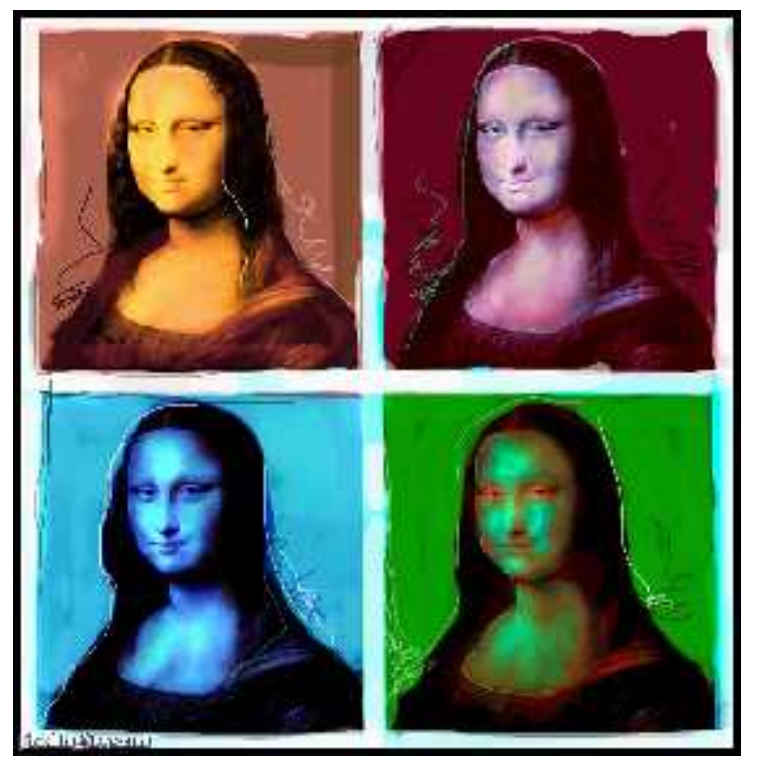

Gambar 2. Monalisa oleh Andy Warhol (Sumber:http://www.freakingnews.com/pictures/405 00/ Mona-Lisa-by-Andy-Warhol--40511.jpg)

Salah satu ciri khas posmodern adalah pluralisme. Dalam paham posmodernisme, perbedaan sangat dijunjung tinggi dan persamarataan sangat diharamkan. Karena bagi mereka, posmodernis, bahwa keseragaman justru akan menghasilkan suatu yang monoton sedangkan hidup dalam perbedaan akan menghasilkan variasi-variasi tersendiri. Selanjutnya posmodern juga melepas estetika, dari persepsi tentang keindahan menuju pada pluralisme makna. ${ }^{12}$

Desain grafis posmodernisme hadir dengan membawa pesan out of context dan out of content, visualisasi tidak lagi dikenalkan dengan cara yang lazim. Desain dikenalkan sebagai produk yang 'abnormal', absurd, dan anomali. Desain dibiarkan bebas mengekspresi pesan dalam bingkai apapun. Visualisasinya tidak lagi mengikuti pola-pola tertentu,

12 Widagdo. (2006). Estetika Dalam Perjalanan Sejarah: Arti dan Peranannya dalam Desain. Dalam JURNAL ILMU DESAIN , Vol 1 No 1. (2006). hlm 3. 
geraknya begitu bebas dan dinamis. Prinsip pesan dan makna tunggal yang berlaku pada modernisme, sudah tidak berlaku pada posmodernisme. Desain dalam posmodern menawarkan ekspresi visual yang memungkinkan terjadinya multipersepsi.

Gen posmodernisme diturunkan pada semua 'anak cucu' desain. Dalam desain komunikasi visual potmodernisme telah memberikan jawaban baru atas kekakuan makna pesan sebagai tujuan utama komunikasi visual. Tipografi tidak lagi menjadi entitas tersendiri tetapi sudah menjadi satu bagian 'keluarga' dengan image. Fotografi tidak lagi ditempatkan sebagai penguat pesan visual, tetapi bisa dibiarkan bicara dengan bahasanya sendiri. Konsep desain tempo dulu dan modern dibiarkan harmonis dalam satu ruang visual. Eksplisitivis pesan bukan lagi primadona, seruan justru banyak menampilkan citra visual. Strinati (2007) mengungkapkan bahwa tampilan permukaan dan gaya menjadi lebih penting, dan pada gilirannya menuntut semacam "ideologi perancang", sebagaimana dikemukakan oleh Harvey: "citraan mendominasi narasi"13.

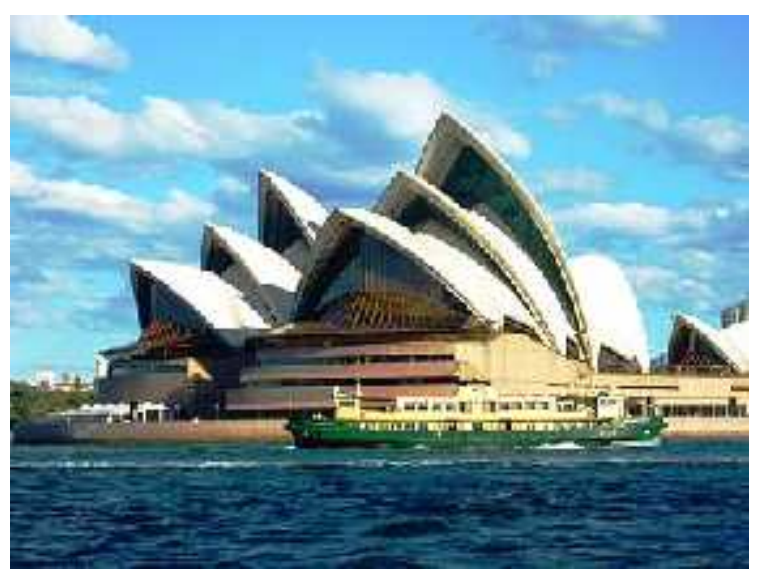

Gambar 3. "Sydney Opera House" (contoh arsitektur posmodern)

(Sumber:https://en.wikipedia.org/wiki/Postmodern_ architecture)

${ }^{13}$ Dominic Strinati. Popular Culture. (Yogyakarta: Jejak, 2007) hlm. 257.
Dunia arsitektur pun tidak terlepas dari pengaruh posmodernisme. Bahkan perkembangannya lebih pesat lagi. Posmodernisme dalam arsitektur menolak metanarasi. Tonggaknya adalah bangunanbangunan yang sangat banyak ornamen, dirancang sungguh-sungguh, dikontekstualkan dan diberi warna cerah, sebuah penekanan pada fiksionalitas dan sifat main-main, serta penggabungan gaya yang diambil dari berbagai periode sajarah yang berbeda dengan cara yang nyaris acak dan eklektis. Posmodernisme mengubah bangunan menjadi perayaan gaya dan permukaan, memanfaatkan arsitektur untuk membuat lelucon tentang ruang yang dibangun ${ }^{14}$.

Posmodernisme dalam dunia periklanan hadir dengan membawa warna baru visualisasi media. Fungsi iklan yang awalnya lebih dimaksudkan untuk kepentingan komersial terus mengalami pergeseran dalam penyajiannya. Iklan tidak lagi secara terangterangan berisi tawaran produk pada para konsumennya, tetapi telah banyak bergeser sebagai seni pertunjukan layaknya film kecil berdurasi sangat singkat.

Advertising Agency pun banyak mengubah konsepnya pada pola-pola lama modernism periklanan, yang menekankan pada kejujuran iklan, kejelasan produk, pencitraan positif, dan prinsip efektivitas pesan. Iklan posmodernisme lebih bebas mengungkapkan gayanya. Malah, strategi periklanan paling strategis bukan hanya bergerak sejalan dengan tetapi juga memasukan zaman kedalam iklan ${ }^{15}$.

Iklan-iklan posmodern lebih banyak berkutat dengan representasi-representasi kultural iklan daripada kualitas produk yang diiklankan yang dimiliki di dunia luar, sebuah kecenderungan unutk tetap bersentuhan dengan tumbangnya "realitas" yang diandaikan di dalam budaya popular. Tampilan iklan yang bergaya, kutipan-kutipan cerdasnya dari budaya maupun seni popular, cerita-cerita mininya, perhatiannya terhadap hal-hal yang bersifat permukaan, sindiran-sindiran yang penuh

${ }^{14}$ Dominic Strinati. Popular Culture. (Yogyakarta: Jejak, 2007) hlm. 262.

${ }^{15}$ Marcel Danesi. Pesan, Tanda, dan Makna. (Yogyakarta: Jalasutra, 2010). hlm. 383. 
kelucuan dengan mengorbankan iklan itu sendiri, penyingkapan secara sadar akan sifat iklan sebagai konstruksi media, maupun pendaurulangan masa lalu secara terangterangan, semuanya itu dapat dikatakan sebagai indikasi lahirnya posmodernisme dalam iklan televisi. ${ }^{16}$

\section{PENUTUP}

Persoalan

modernisme maupun posmodernisme dalam desain pada akhirnya tidak bisa dipisahkan dari perkembangan kebudayaan manusia. Selama manusia mengalami perkembangan budaya maka selama itu pula sejarah desain akan berubah-ubah. Baik modernisme maupun posmodernisme, keduanya telah menempati wilayahnya masingmasing yang mesti dipandang dari sisi yang positif, yakni telah berperan besar dalam perkembangan dunia desain.

Dalam realita yang nampak pada karya desain yang ada sekarang, sulit rasanya untuk melakukan 'pengotakan' terhadap blok modern dan posmodern. Apakah karya ini 'modern' atau 'posmodern', atau bahkan campuran keduanya, lalu akan disebut apa, akan sulit untuk menerjemahkannya. Batasan sejarah hanya digunakan sebagai alat ukur agar desain bisa dipahami dalam sudut pandang keilmuan. Sementara realita tidak bisa sepenuhnya dinilai oleh sejarah.

Seiring dengan waktu, cara pandang terhadap definisi desain, ide dan konsep desain, batasan-batasan desain pun akan terus mengalami perubahan. Sampai sejauh ini ramalan-ramalan tentang masa depan setelah posmodern baru bergulir dalam wacana-wacana pada budaya, seni, desain, dan sastra. Apa yang akan terjadi setelah masa posmodern nampaknya sulit untuk diprediksi.

Dunia desain --terlepas dari modernism dan posmodernisme-- tetap akan selalu menempati bagiannya dalam peta sejarah kebudayaan manusia sampai kapanpun. Para desainernya akan selalu menjadi bagian dari perubahan budaya agar dunia ini semakin indah dan bermakna.

\footnotetext{
${ }^{16}$ Dominic Strinati. Popular Culture. (Yogyakarta: Jejak, 2007) hlm. 267.
}

\section{REFERENSI}

Danesi, M. (2010). Pesan, Tanda, dan Makna. Yogyakarta: Jalasutra.

Hartley, J. (2010). Communication, Cultural, \& Media Studies. Yogyakarta: Jalasutra.

http://id.wikipedia.org/wiki/Modernisme. (n.d.). Retrieved December 20, 2013, from id.wikipedia.org.

Strinati, D. (Popular Culture). 2007. Yogyakarta: Jejak.

Thwaites, T., Davis, L., \& Mules, W. (2009). Introducing Cultural and Media Studies. Yogyakarta: Jalasutra.

Wahyudi, G. (2011, May 5). http://gemawahyudi.wordpress.com/2011/0 5/05/modernisme-dan-posmodernismepengaruhnya-terhadap-dunia-desain/. Pengertian tentang posmodernisme ini diambil dari buku Charles Jencks (1989). What is Pos-modernism ? New York: St Matin's Press. Retrieved December 20, 2013, from http://gemawahyudi.wordpress.com.

Widagdo. (2005). Desain dan Kebudayaan. Bandung: Penerbit ITB.

Widagdo. (2006). Estetika dalam Perjalanan Sejarah: Arti dan Peranannya dalam Desain. Jurnal Ilmu Desain, 3. 